\title{
Contribuições de Métodos de Ensino para o Desenvolvimento da Leitura à Primeira Vista ao Piano ${ }^{1}$
}

\author{
Contributions of Teaching Methods for the Development of Piano Sight-Reading
}

\author{
Marcelo Almeida Sampaio \\ Universidade do Estado de Minas Gerais, Belo Horizonte, Brasil \\ marsampaio@hotmail.com
}

\section{Patrícia Furst Santiago}

Universidade Federal de Minas Gerais, Belo Horizonte, Brasil

patfurstsantiago@gmail.com

\begin{abstract}
This article presents an analysis of piano methods of sight-reading, which were elaborated by nine significant authors of piano pedagogy. Piano sight-reading is understood as a specific competence that requires high cognitive and physical performance. For its full development, reading at first glance requires specific practice, which evolves the integration of a multitude of aspects. Some of these aspects are subject of the analysis that the article offers, such as: reading notes, technique, rhythmic training, repertoire, other tooth. It is concluded that the acquisition of a competence in piano sight-reading is not only achieved through the study of the instrument or the performance of pianistic works, but requires a specialized pedagogy for its full development.
\end{abstract}

Keywords: piano methods for sight-reading; teaching strategies in music.

Resumo: Este artigo apresenta uma análise dos métodos de leitura à primeira vista ao piano elaborados por nove autores significativos da pedagogia do piano. A leitura à primeira vista é uma competência específica que requer alto desempenho cognitivo e físico. Para seu pleno desenvolvimento, a leitura à primeira vista exige de pianistas uma prática específica que envolve a integração de uma infinidade de aspectos. Alguns desses aspectos são temas da análise que o artigo oferece, tais como: leitura de notas, técnica, treinamento rítmico, repertório, dentre outros. Conclui-se que a aquisição de uma competência em leitura à primeira vista não é alcançada apenas com o estudo do instrumento ou com a execução de obras pianísticas, mas requer uma pedagogia especializada para o seu pleno desenvolvimento.

Palavras-chave: métodos de piano para leitura à primeira vista; estratégias de ensino em música.

Data de submissão: 20 Fevereiro 2018

Data final de aprovação: 20 Maio 2018

\footnotetext{
1 Este artigo é parte da pesquisa de doutorado em Leitura à primeira vista patrocinada pelo Programa PCRH da FAPEMIG (2013) e pelo Programa de Bolsa-Sanduíche no Exterior do CNPq (2015).
} 


\section{1 - Leitura à primeira vista ao piano: problemáticas e propostas}

A formação de pianistas profissionais abrange uma série de conhecimentos, habilidades, comportamentos e atitudes que, desenvolvidos de forma integrada, levam à construção de um perfil profissional competente. Dentre esses componentes, a competência da leitura à primeira vista (LPV) é bastante exigida, tanto para pianistas solistas quanto para pianistas colaboradores, cameristas, ensaiadores, arranjadores, compositores e regentes. Para os pianistas, a prática da LPV em nível profissional torna-se um diferencial importante no mercado de trabalho, por possibilitar a eles habilidades como a aceleração do seu ritmo de estudo, a prontidão para ensaios e a preparação de performances de última hora. LEHMANN e McARTHUR (2002, p.149) explicam:

[A leitura à primeira vista] oferece aos músicos uma possibilidade de sobreviver em uma situação econômica que exige a habilidade de aprender música rapidamente, quando não à primeira vista. Ela também possibilita que músicos de todos os níveis toquem em conjunto para sua própria satisfação bem como para a dos outros.

Ler à primeira vista é atividade que requer alto desempenho cognitivo e motor. Sua ação exige processamento de várias camadas interdependentes, a saber:

a) cognitiva-genérica: na atenção, percepção e memória;

b) cognitiva-visual: no reconhecimento das notas e de sua relação com padrões aprendidos (melódicos, rítmicos, harmônicos e outros).

c) cognitiva-auditiva: na escuta das melodias e sua identificação na escrita da partitura;

d) motora: na coordenação entre o movimento dos olhos, mãos e pés e o conteúdo da partitura.

Para os pianistas, o processo de decodificação do texto musical é problemático desde o estágio inicial, quando se estabelecem os primeiros contatos com a notação, até estágios avançados, quando a leitura integra conhecimentos interpretativos, simbólicos e artísticos. No ensino e prática da LPV, em um contexto universitário, alguns problemas gerais são percebidos. Um deles é a inabilidade cognitiva dos alunos em compreender de imediato os signos gráficos contidos na partitura e executá-los no instrumento. Frequentemente, essa habilidade se mostra insuficiente, tanto na realização motora quanto no entendimento de padrões no agrupamento das notas. Essa relação é complexa, pois envolve uma interação olho-cérebro-ouvido-mãos, além de outros fatores que por si mesmos interferem no sucesso da tarefa (SANTIAGO e SAMPAIO, 2014, p.273-275; SAMPAIO, 2017, p.9). Outro problema é a falta da integração das diversas habilidades envolvidas na LPV, relacionadas a múltiplos fatores, tais como o monitoramento visual e auditivo de conteúdos da partitura; o uso de dedilhados; o domínio dos aspectos técnicos; a compreensão de estilos; o uso dos pedais; o tocar sem interrupções e sem correção de erros, dentre outros. A existência desses dois problemas na performance de estudantes universitários - daquela inabilidade cognitiva dos alunos e da falta da integração das diversas habilidades envolvidas na LPV - indica a necessidade de um entendimento mais profundo quanto ao ensino e às práticas pedagógicas na formação da LPV de pianistas, permitindo a construção de ações mais eficazes para o seu desenvolvimento.

A primeira questão a ser tratada sobre a LPV diz respeito ao seu próprio conceito. LPV requer definições mais claras, uma vez que vários autores divergem entre si sobre seu significado, o 
que torna fragmentado o próprio conceito quando se misturam os componentes da leitura com os procedimentos pedagógicos a serem aplicados no domínio dessa competência. GABRIELSSON (1999, p.508) compreende a LPV como a habilidade de tocar no instrumento os signos de uma partitura sem nenhuma preparação anterior: uma "combinação de leitura e comportamento motor, isto é, ler padrões de notas que surgem na partitura enquanto se tocam outras que acabaram de ser lidas". LEHMANN e McARTHUR (2002, p.141), por outro lado, a consideram "uma performance com ou sem ensaio". ROSEMANN et al. (2015, p.1) concordam com esses autores e acrescentam que a LPV "exige uma fixação antecipada de notas, seguida imediatamente por uma execução motora”. LEHMANN, SLOBODA e WOODY (2007, p.108) a consideram como "algo que acontece online, um fato com que o executante tem que lidar usando estratégias apropriadas".

É interessante notar que a literatura existente, tanto na pesquisa acadêmica quanto em diversos métodos de LPV publicados para piano, oferece outros conceitos referentes a práticas complementares à LPV. Por exemplo, RAMOS $(2005$, p.2) considera a leitura prévia como algo diferente da LPV. Para ela, leitura prévia é uma "observação minuciosa da partitura, antes de ser tocada ou cantada e pela realização, fora do instrumento, de determinadas estruturas da partitura, por meio do solfejo e da ação combinada". Esse processo consiste em estratégia pedagógica fundamental à LPV, pois possibilita que pianistas usem o escaneamento de determinadas estruturas antes de executar um texto musical. FOURIE (2004, p.1) acrescenta outros conceitos como as respostas motoras à percepção da notação, a audiação ou ouvido interno durante processo. PIKE (2011 p.42) inclui a capacidade de agrupamento de notas em unidades perceptivas mais significativas. LEHMANN, SLOBODA e WOODY (2007, p.108), por sua vez, mostram diferenças interessantes entre LPV, tocar de ouvido (TO) e tocar uma performance memorizada (TPM). A Figura 1, a seguir, sintetiza essas diferenças.

\begin{tabular}{|c|c|}
\hline $\begin{array}{c}\text { Leitura à primeira vista (LPV) } \\
\text { Tocar de ouvido (TO) }\end{array}$ & $\begin{array}{c}\text { Tocar uma perfórmance } \\
\text { memorizada (TPM) }\end{array}$ \\
\hline Música não familiar & Música familiar \\
\hline $\begin{array}{l}\text { LPV: Traduz a notação em uma } \\
\text { perfórmance em tempo real. }\end{array}$ & \multirow{2}{*}{$\begin{array}{l}\text { Recupera da memória a música e } \\
\text { os programas motores. }\end{array}$} \\
\hline $\begin{array}{l}\text { TO: Traduz sons e movimentos em } \\
\text { perfórmance. }\end{array}$ & \\
\hline $\begin{array}{l}\text { LPV: Produz expressão in loco, } \\
\text { consequentemente menos } \\
\text { artística. }\end{array}$ & \multirow{2}{*}{$\begin{array}{l}\text { Apoia-se em uma interpretação } \\
\text { artística cuidadosamente } \\
\text { planejada. }\end{array}$} \\
\hline $\begin{array}{l}\text { TO: Copia a expressão, pode talvez } \\
\text { modificar-se mais tarde. }\end{array}$ & \\
\hline LPV: Suposição e inferência. & \multirow{2}{*}{ Tudo é conhecido previamente. } \\
\hline TO: Tentativa e erro. & \\
\hline $\begin{array}{l}\text { LPV: O monitoramento visual } \\
\text { contínuo não é sempre possível. }\end{array}$ & \multirow{2}{*}{$\begin{array}{l}\text { O instrumento pode ser contínua e } \\
\text { visualmente monitorado. }\end{array}$} \\
\hline $\begin{array}{l}\text { TO: O monitoramento visual } \\
\text { contínuo é possível. }\end{array}$ & \\
\hline Tende a ser mais flexível. & Tende a ser menos flexível. \\
\hline $\begin{array}{l}\text { Tende a ser mais lento } \\
\text { (inicialmente). }\end{array}$ & Tende a ser mais rápido. \\
\hline Tende a ser menos preciso. & Tende a ser altamente preciso. \\
\hline
\end{tabular}

Figura 1: Comparação entre leitura à primeira vista (LPV), tocar de ouvido (TO) e tocar performance memorizada (TPM). (LEHMANN, SLOBODA e WOODY, 2007, p.108).

Os conceitos e observações acima dão suporte à típica complexidade da LPV, sua ação online, seus aspectos cognitivos de previsão e de monitoramento visual, seus aspectos motores usados para decodificar os signos escritos em sons, através da prática deliberada a longo prazo. Por 
fim, como síntese, definimos a leitura à primeira vista como a percepção de um texto musical em que processos cognitivos e comportamentos motores são convertidos em uma performance sonora sem ensaio prévio.

Dentro de um quadro tão complexo, uma quantidade e variedade significativa de material pedagógico tem sido elaborada por pedagogos para atender às demandas de formação tão ampla exigida pela prática da LPV. Para tal, nesse estudo, foram analisados os métodos dos seguintes autores que produziram, em nível nacional e internacional, material pedagógico de LPV para piano:

De tradição alemã:

a) KEILMANN (1972, 1975). Introduction to sight-reading: at the piano or other keyboard instrument;

De origem brasileira:

b) BUCHER (2009). Leitura à primeira vista: a ciência da conquista;

De tradição francesa:

c) MANTAUX (2006). Méthode de déchiffrage pour piano;

d) MEYER-GARFORTH (1984). Cours progressive de déchiffrage pour le piano;

De tradição inglesa:

e) JOHNSON (2001). Right a sight;

f) $\operatorname{KEMBER}(2004,2005,2006,2010)$. Piano sight-reading: a fresh approach;

g) HARRIS (2008). Improve your sight-reading!;

h) BULLARD (2010). Joining the dots: a fresh approach to piano sight-reading;

i) RILEY e TERRY (2012). Sight reading success.

Esses autores foram escolhidos por adotarem tendências relativamente diferentes no ensino e prática da LPV. 0 alemão KEILMANN $(1972)^{2}$ propõe, antes da sensação visual, um interessante estudo da sensação tátil do teclado. Ele propõe também o estudo visual de agrupamentos de notas a partir de parâmetros escalares e intervalares. MANTAUX (2006) e MEYER-GARFORTH (1984), de tradição francesa, desenvolvem sua prática da leitura a partir do intervalo de $2^{\mathrm{a}}$ ampliado até à 8*a . Os outros autores, JOHNSON (2001), KEMBER (2004), HARRIS (2008), BULLARD (2010), e RILEY e TERRY (2012) têm tradição inglesa que estabelece níveis mais graduais e mais detalhados de dificuldade, adotando parâmetros definidos pela tradicional $\mathrm{ABRSM}^{3}$, seguindo sua progressão centrados nas tonalidades definidas e aprendidas em cada etapa. Os autores ingleses são altamente recomendados, principalmente por sua construção pedagógica em etapas bastante graduais e pela variedade de material específico publicado. As autoras francesas desenvolvem mais a leitura por distanciamento intervalar sem o uso de

\footnotetext{
${ }^{2}$ Este método teve sua análise bem explorada no trabalho de Risarto: RISARTO, 2010, p.39-60.

${ }^{3}$ A Associated Board of the Royals Schools of Music (ABRSM) existe há mais de 120 anos, envolvendo instituições de renome internacional como o Royal Academy of Music, o Royal College of Music, o Royal Northern College of Music e o Royal Conservatoire of Scotland, e publica bianualmente o syllabus, um conjunto predefinido de oito níveis nos quais estão descritas atividades relacionadas à aprendizagem musical nos campos da Teoria Musical, LPV, Testes Auditivos, Performance e outras áreas para todos os instrumentos além do piano. Acesso ao programa $\begin{array}{lcrl}\text { completo } & \text { pode } & \text { ser } & \text { feito }\end{array}$ http://gb.abrsm.org/fileadmin/user_upload/syllabuses/pianoSyllabusComplete17.pdf
} 
recursos, tais como livro de atividades e elaboração de exercícios para o aluno. 0 autor alemão propõe mais ideias gerais e conceitos do que exercícios em etapas gradualmente planejadas. Curiosamente, no Brasil, foi encontrada apenas uma publicação pedagógica recente, específica sobre LPV ao piano: BUCHER (2009). Isto nos leva a crer que esse tema tem sido pouco discutido no país, e que materiais pedagógicos não têm sido publicados por professores de piano para atender à formação de pianistas.

Neste artigo, procuramos sintetizar, na análise dos métodos, os conteúdos mais relevantes que representam as preocupações de seus autores quanto ao ensino de LPV ao piano. As categorias adotadas para a análise são as seguintes: estratégias e princípios para a prática e desenvolvimento da LPV; leitura de notas e ritmo; aspectos técnicos; repertório; práticas. Na seção a seguir, detalharemos cada um desses aspectos.

\section{2- Análise dos métodos de LPV ao piano}

\section{1 - Estratégias e princípios para a prática e desenvolvimento da LPV}

Essa categoria de análise é composta de três subcategorias: (1) estratégias de prática "regras de ouro"; (2) progressividade e (3) recursividade.

As estratégias de prática ou "regras de ouro" são assim denominadas por HARRIS (2008, p.24). Nesse sentido, os nove métodos analisados discriminam algumas estratégias fundamentais. Dentre as mais citadas estão:

a) não olhar para o teclado, mas sim para a partitura (KEMBER, 2004; RILEY e TERRY, 2012);

b) olhar adiante (HARRIS, 2008); sentir o pulso ou usar o metrônomo (HARRIS, 2008; RILEY e TERRY, 2012);

c) realizar treinamento rítmico antes da leitura da peça (RILEY e TERRY, 2012);

d) preparar o posicionamento das mãos sobre o teclado para conferir visualmente o dedilhado, antes de executar a peça (KEMBER, 2004; HARRIS, 2008; RILEY e TERRY, 2012);

e) ouvir a execução da peça e depois repeti-la ao piano (no CD, em RILEY e TERRY, 2012);

f) ignorar os erros e seguir em frente (HARRIS, 2008);

g) buscar por padrões de ritmos, notas repetidas, saltos dos intervalos, direção melódica ascendente ou descendente e dedilhados (KEMBER, 2004; HARRIS, 2008; RILEY e TERRY, 2012).

Quanto aos princípios que orientam a pedagogia da LPV, dois se destacam nos métodos analisados: a progressividade e a recursividade. A progressividade na ordenação das práticas de LPV está presente em todos os nove métodos analisados, sendo, portanto, um princípio básico que permeia todos eles. Entende-se progressividade como algo que parte de elementos mais simples e se torna mais complexo ao longo das etapas e em vários aspectos, tais como na apresentação dos conceitos dos intervalos e das figuras rítmicas, na condução do treinamento motor, no uso dos dedilhados. De maneira geral, nos oito volumes dos métodos da ABRSM, inicia-se o conceito dos intervalos a partir de $2^{\underline{a}}$ s e $3^{\underline{a}} \mathrm{~s}$, estendendo-se até o pentacórdio com o intervalo de $5^{\underline{a}}$ (níveis 1 a 3) e, posteriormente, amplia-se para o intervalo de 8ª (níveis 4 e 5) e mais além da 8ª (a partir do nível 6); as figuras rítmicas se iniciam com mínimas e semínimas 
em compassos simples (nível 1) e se complexificam em colcheias, semicolcheias (níveis 2 e 3), introduzindo-se compassos compostos, síncopes, figuras pontuadas (nível 4 em diante). 0 treinamento motor começa com a posição fechada da mão no pentacórdio, com mãos alternadas (nível 1), ampliando-se posteriormente para as mãos simultâneas (nível 2), estendendo-se até a 8 ${ }^{-}$(a partir do nível 4). 0 dedilhado segue o mesmo processo que a leitura intervalar, começando com graus conjuntos e ampliando-se em saltos de $3^{\underline{a}} \mathrm{~s}, 4^{\underline{a}} \mathrm{~s}$ e $5^{\underline{a}} \mathrm{~s}$ até se completar na 8a esse estendendo além dela nos volumes finais.

Particularmente em RILEY e TERRY (2012), pede-se ao aluno que siga a ordem de apresentação do método; ao fim de cada página, ele deve marcar um $x$ no quadrado em branco, confirmando que completou a tarefa proposta. Em HARRIS (2008), a progressividade é feita regularmente, com exceção do estudo de acordes.

A recursividade é outro princípio comum a vários desses autores (MEYER-GARFORTH, 1984; HARRIS, 2008; BULLARD, 2010). BULLARD (2010) e JOHNSON (2001), por exemplo, retomam a cada volume, as tonalidades apresentadas gradualmente, em nível crescente de dificuldade, nos volumes anteriores. Por outro lado, há dentre eles, métodos não-recursivos, tal como o de KEILMANN (1972).

\section{2 - Leitura de notas e ritmo}

Nesta categoria, estão incluídos os seguintes itens: leitura prévia; abordagens de leitura de notas e ritmo (Dó Central, intervalar, livre, explicados adiante); amplitude intervalar; percepção visual da partitura; apresentação dos valores e durações das figuras rítmicas e treinamento rítmico; polifonia.

A leitura prévia é feita de duas maneiras por todos os autores: a) de forma dinâmica, com perguntas ao aluno, ao longo dos volumes, como em JOHNSON (2001), KEMBER (2004), HARRIS (2008) e BULLARD (2010); ou b) de maneira teórica, a partir de orientações escritas ao professor, como em MEYER-GARFORTH (1984) e BUCHER (2009). HARRIS (2008) pede ao aluno que observe as fórmulas de compasso e tonalidade, a distância intervalar e seu preenchimento com notas e padrões simples da melodia e ritmo. RILEY e TERRY (2012) endossam essas ideias, recomendando ao aluno para atentar-se aos aspectos visuais importantes marcados no livro com uma setinha preta, tais como indicações de dinâmica, mudanças no dedilhado, organização e agrupamento rítmico. KEMBER (2004) recomenda ao aluno olhar o número de sustenidos e bemóis nas claves; contar regularmente à medida que se toca; sempre tocar expressivamente; escanear a peça e verificar as mudanças nos compassos, estabelecendo previamente o andamento a ser executado e conscientizar-se da forma dos acordes. KEILMANN (1974, volume 2) sugere outras inspeções, como as mudanças de clave e saltos das mãos. MANTAUX (2006) é a única que não usa a leitura prévia.

Nos métodos analisados, as abordagens para a leitura de notas e ritmos são duas: Dó Central e abordagem livre. Com exceção da abordagem livre de KEILMANN (1972), todos os autores desenvolvem a leitura na pauta a partir da abordagem Dó Central. Essa abordagem preconiza o Dó central (Dó 3) como nota de referência, tanto na pauta quanto no piano, limitando-se à 
região média do instrumento. As alturas são identificadas a partir do nome da nota acima ou abaixo do Dó 3 e assim, a leitura vertical se faz pela agregação de notas (por exemplo, Dó-MiSol, na mão direita; Fá-Lá-Dó, na mão esquerda), gerando o pentacórdio por espelhamento das mãos (SAMPAIO, 2001, p.39-40).

Em alguns métodos, a amplitude intervalar das peças se mantém no âmbito da $5^{\mathrm{a}}$ sem passagem do polegar (JOHNSON, 2001; RILEY e TERRY, 2012). Posteriormente, introduz-se a ampliação da posição fechada dos dedos sem passagem de polegar (RILEY e TERRY, 2012). E, mais tarde, a passagem de polegar propriamente dita (JOHNSON, 2001; RILEY e TERRY, 2012).

Nos que diz respeito à percepção visual da partitura, há algumas particularidades apresentadas nos métodos analisados. Por exemplo: nas percepções visuais da partitura, dois autores sugerem sinais gráficos para estimular o olhar adiante e o reconhecimento de padrões melódicos. Em MANTAUX (2006), o uso intencional de notas coloridas foca o olhar para a distribuição do intervalo na pauta (Figura 3) ou a fermata que prepara o aluno para olhar adiante o arpejo ou o grupo de notas diatônicas, sem tocá-los imediatamente (Figura 4). Em KEILMANN (1972), além de usar a fermata e pedir para o aluno olhar adiante, ele também indica em uma legenda (Figura 5) o uso de colchetes horizontais quais são o primeiro e o segundo motivos fraseológicos de um trecho musical e, com uma curva tracejada, identifica os motivos estendidos ou modificados relacionados aos dois anteriores.
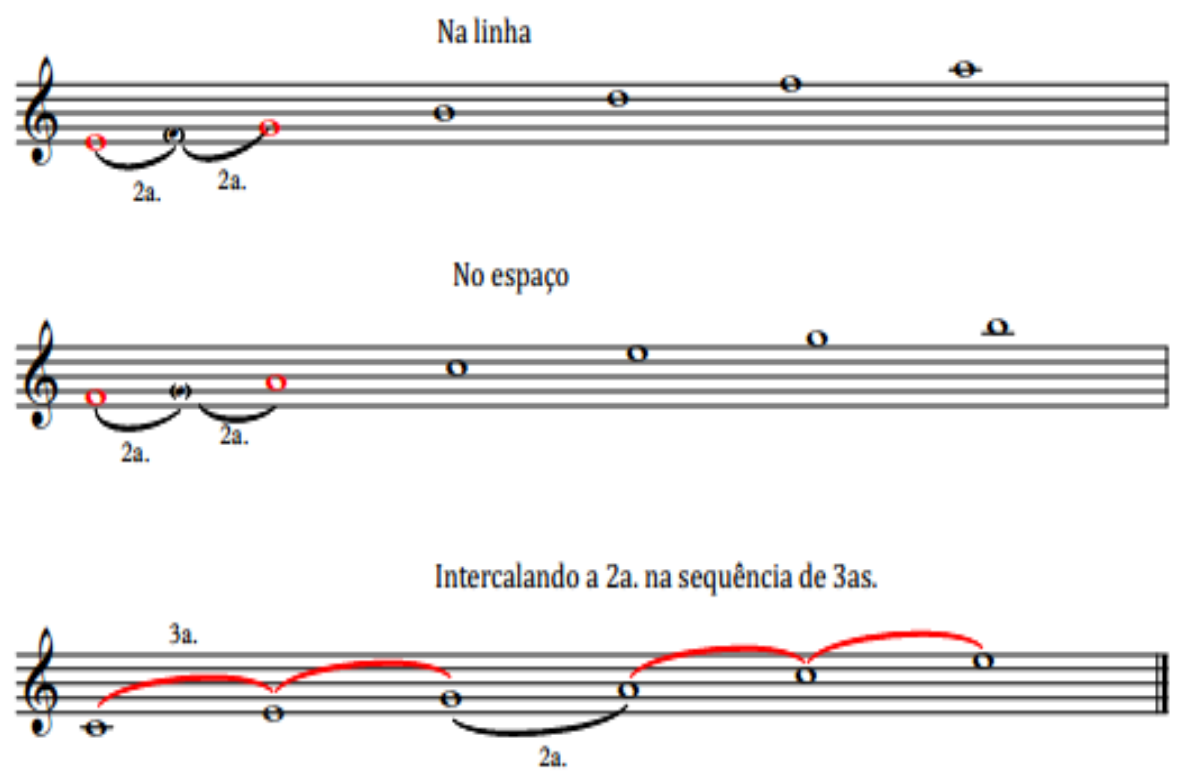

Figura 3: Utilização de cores em notas, ligaduras e intervalos, mostrando a mudança de configuração visual na 'linha' ou no espaço (MANTAUX, 2006, p.13). 


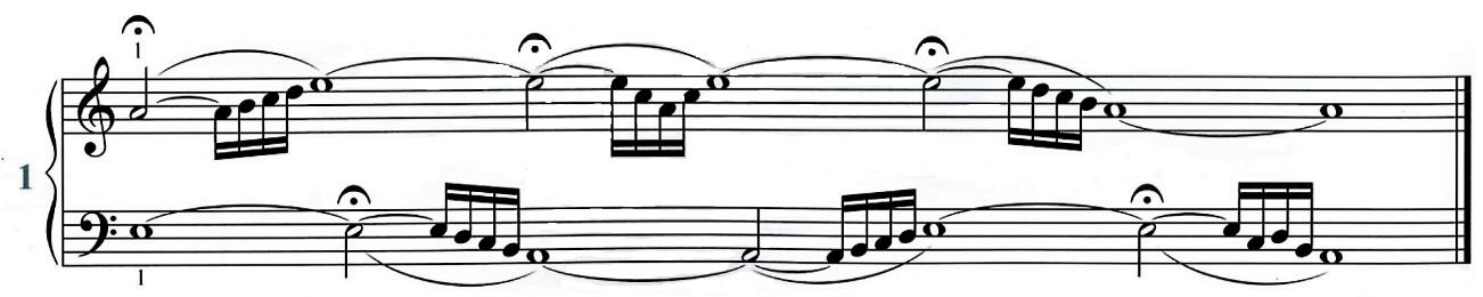

Figura 4: Apresentação visual da fermata que facilita o olhar adiante na partitura, com a alternância da performance das semicolcheias. (MANTAUX, 2006, p.13).

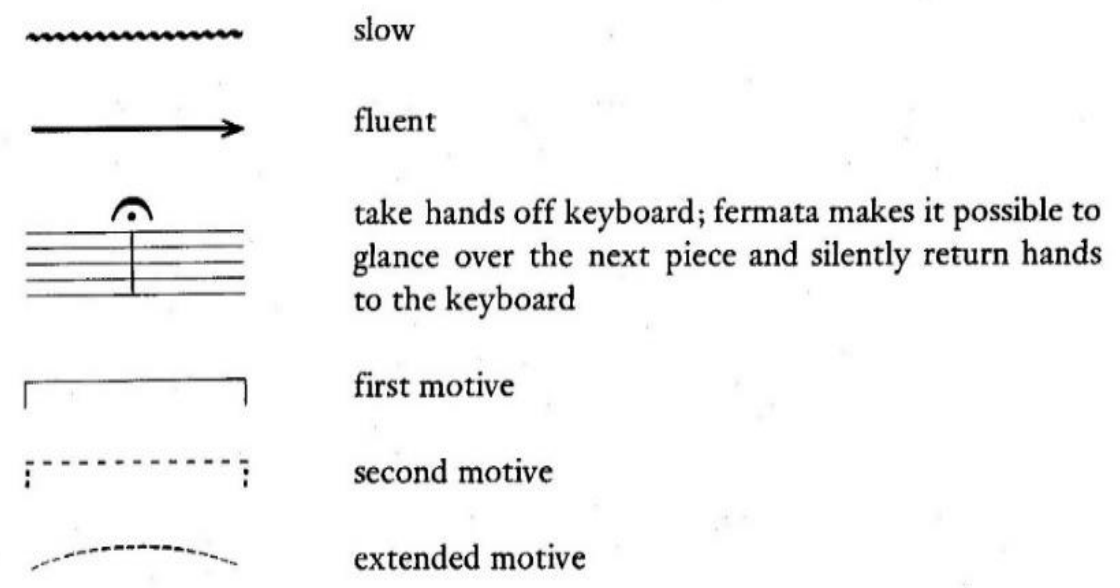

Figura 5 - Legenda das marcações para reconhecimento de padrões na partitura: 'lento; fluente; tirar as mãos do teclado; a fermata permite dar uma olhada para a próxima peça e, silenciosamente, retornar as mãos ao teclado; primeiro motivo; segundo motivo; motivo estendido. ' (KEILMANN, 1972, p.27).

Para a apresentação dos valores e duração das figuras rítmicas, assim como MEYER-GARFORTH (1984), BUCHER (2009) adota repertório em compassos simples binário, ternário, quaternário e composto binário, mas não explora outras combinações, como o compasso quinário, em sete tempos, e o compasso composto em nove e doze tempos. Por outro lado, os autores ingleses exploram essas variedades rítmicas ao longo de seus métodos e são os que têm mais cuidado na apresentação de figuras rítmicas apresentadas aos alunos passo a passo. 0 parâmetro ritmo representa um aspecto prioritário em relação aos demais, pois é ele que direciona o "não parar", o "não atrasar" e o "não acelerar", condições fundamentais para uma boa leitura à primeira vista.

No que diz respeito ao treinamento rítmico, não há variedade na forma musical, mas apenas nas abordagens ${ }^{4}$ (SAMPAIO, 2001, p.43) para se praticar as configurações rítmicas dadas no repertório. KEILMANN (1972, p.23-24) é o único que usa a contagem silábica (sílabas da e ra, Figura 6). Ele propõe o estudo separado dos processos rítmicos, recomendando que se identifiquem passagens rítmicas difíceis, comparando os valores das durações das notas a

\footnotetext{
${ }^{4}$ As abordagens para a contagem do ritmo são: 1) aritmética: aquela que estabelece o valor numérico no tempo, de acordo com a fórmula de compasso, e usa a palavra $e$ nas subdivisões do compasso. (1 e 2, 3, 4 e 1, 2...) 2) funcional ou por unidade: aquela que considera cada semínima como um tempo, a mínima como dois e assim por diante, conforme a fórmula de compasso. $(1,1,1-2, \ldots)$ 3) silábica: a feita com quaisquer sílabas neutras, tais como tá, ná, na-á, tá-tei, da mesma forma que a contagem por unidades, sem preocupação com a enumeração continuada dos tempos.
} 
partir do valor rítmico mais curto e praticando-os com palmas e voz. Os ingleses e MEYERGARFORTH (1984) adotam a contagem aritmética, geralmente com pés marcando a pulsação e as palmas realizando as configurações da melodia e BUCHER (2009) sugere a contagem funcional. KEMBER (2004) e MANTAUX (2006) não usam nenhum treinamento à parte.

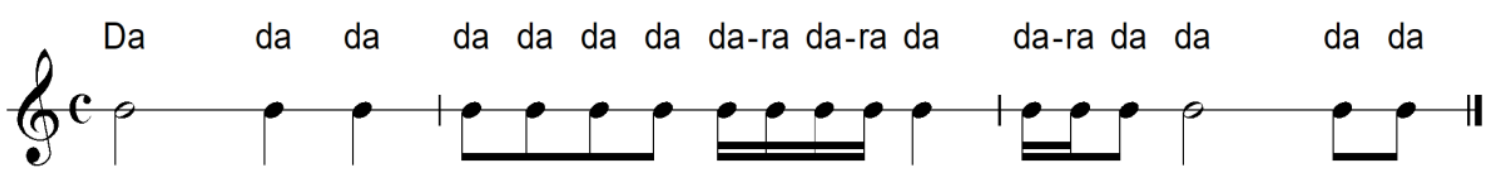

Figura 6 - Contagem silábica usando as sílabas da e ra (KEILMANN, 1972, p.23).

Na abordagem da leitura da polifonia, MANTAUX (2006) e HARRIS (2008, volume 8) mostram como essa textura musical a três e quatro vozes pode ser entendida. Esses são os únicos autores que expõem a textura como algo a ser considerado na LPV. Os outros métodos nem sequer apresentam esse tema.

\section{3 - Aspectos técnicos}

Em relação aos aspectos técnicos, os métodos enfatizam dois conteúdos: coordenação das mãos e dedilhado. Na coordenação das mãos, há unanimidade dos autores em se iniciar o repertório com mãos alternadas. Depois, as mãos tocam juntas, inicialmente de forma estática, com a mão esquerda tocando figuras rítmicas longas e a direita em movimentação ou vice-versa. Por fim, o contraponto fica mais intensificado, com nota contra nota em tipos diferentes de configurações. Os autores ingleses cuidam desse aspecto de forma mais gradativa que as autoras francesas. 0 autor alemão começa com mãos juntas.

Quanto ao dedilhado, em alguns métodos, não há ordem gradual de dificuldade, como é o caso de BULLARD (2010). Já nas primeiras lições, o autor propõe a abertura da extensão dos dedos fora da posição fechada e usa a passagem precoce do polegar, feita com o dedo indicador em passagens descendentes na mão direita e dedo anular em passagens descendentes na mão esquerda. Isto se justifica, possivelmente, para que o aluno possa tocar em curto prazo uma melodia em toda a extensão de oitava referente à tonalidade aprendida. Já a abordagem de HARRIS (2008) e JOHNSON (2001) é feita pelos intervalos de segundas, terças e quartas e encerra nas quintas, concluindo na posição fechada da mão em pentacórdio, sem passagem do polegar. Somente a partir do volume 3, o autor amplia o uso do dedilhado, abrindo a posição de mão fechada para aberta sem passagem de polegar, e depois adicionando-a. Diferentemente, em KEMBER (2008), o dedilhado no volume 3 foi omitido propositalmente para estimular no aluno a independência em postar a mão por si mesmo, baseado nas formas dos intervalos e acordes anteriormente aprendidos. 


\section{4 - Repertório}

Em relação ao repertório, destacamos na análise dos métodos os seguintes itens: escolha do repertório; estilos musicais; formas escalares; o uso de atividades complementares.

No que diz respeito à escolha do repertório, há algumas semelhanças e diferenças importantes nos quesitos autoria, gêneros, forma e variedade das peças. Nos métodos ingleses e franceses, as peças são todas compostas pelos próprios autores sem referência a outros compositores conhecidos. Alguns adotam repertório variado em gêneros e formas específicos, tais como o tema com variações, ABA, rondó (RILEY e TERRY, 2012; BULLARD, 2010); o baixo d'Alberti e o walking bass de uso extenso no jazz (HARRIS, 2008); variações, forma-sonata, dentre outras (KEILMANN, 1972). Por outro lado, MEYER-GARFORTH (1984) não explora o conceito e a prática de gêneros, mas nomeia as peças com o nome de gavota, minueto e valsa. Interessante é notar que KEMBER (2004), embora adote repertório variado, não o apresente em gêneros musicais específicos ou formações escalares diversas. Outros métodos propõem repertório pouco variado, como são os casos de MEYER-GARFORTH (1984) e de JOHNSON (2001), que apresenta peças bastante semelhantes entre si. Em seu volume 1, KEILMANN (1972) não é musicalmente estimulante, pois ele propõe exercícios em detrimento de um repertório musical. Somente no volume 2, o autor usa peças de compositores do período do barroco ao romântico (Bach, Mozart, Mussorgsky, Brahms, para citar alguns) e explora o repertório para piano solista e música de câmara em um grau mais avançado de execução. Ainda assim, não são explorados repertórios além da tradição tonal ocidental, prática que enriqueceria não apenas a leitura, mas a escuta diferenciada de outros sistemas musicais.

A LPV de diferentes estilos musicais é assunto pouco explorado. Nesse sentido, seu aproveitamento é dado apenas em KEMBER (2004, v.3), com uma coletânea de peças do período clássico e romântico e escassamente em MANTAUX (2006, capítulo 18), a partir de padrões de células repetitivas. BULLARD (2010) treina melhor, como a mazurca e o minueto, em peças para compor, mas é mais focado em composição livre do que em um estilo propriamente dito.

Ainda, quanto à escolha do repertório, HARRIS (2008) apresenta regularmente uma coletânea de trechos de pequenas peças ${ }_{\llcorner}$integrando os conteúdos aprendidos em quatro atividades: exercícios rítmicos; exercícios melódicos; "tocando solo" e "peças preparadas". Assim como em JOHNSON (2001), essas últimas são exemplos que impulsionam a prática da leitura prévia do repertório a partir de perguntas escritas ao aluno sobre tonalidade, padrões rítmicos e melódicos, escolha de um caráter expressivo para a melodia.

Quanto às formas escalares, alguns exploram escalas exóticas. Este é o caso de BULLARD (2010) que usa a escala pentatônica e a escala de jazz (também usada nos últimos volumes de HARRIS, 2008). Por outro lado, outros métodos não exploram formas escalares diversas, como é o caso de JOHNSON (2001). Nesse aspecto, o uso das escalas pentatônica, hexafônica, escalas de jazz e blues, bem como escalas modais, poderia enriquecer a leitura, a escuta e a variedade musical das peças.

Nos métodos analisados, o uso de atividades complementares é escasso. Apenas RILEY e TERRY (2012) anexam como atividade complementar um CD ao livro, no qual as mesmas instruções 
dadas pelo texto escrito se repetem verbalmente na gravação. Também se encontra no CD a performance de todas as peças escritas pelos próprios autores. Com o uso do CD, cria-se uma relação pedagógica importante que é a construção interativa entre a modalidade auditiva e a visual, permitindo ao aluno, desde o início, a formação de estruturas para a audiação. BULLARD (2010) também adota atividades complementares para reforçar a noção e a sensação da tonalidade, a formação das escalas e os acordes quebrados, bem como exercícios de aquecimento dos dedos e mãos, com exploração de alguma competência técnica. Esses exercícios são apresentados em pares, com o primeiro par exatamente igual em todos os volumes, transposto apenas para as diferentes tonalidades; o segundo par é diferente, apresentando um determinado desafio explicado pelo autor. Ele propõe ainda atividades de LPV propriamente ditas, feitas a partir de orientações dadas antes de o aluno tocar. As peças são relacionadas com as tonalidades do nível referente. Algumas delas apresentam o acompanhamento de um dueto a ser tocado pelo aluno com o professor. Existe alternância dos papéis de primo e seccondo, com o aluno lendo duas claves de Sol ou duas de Fá. Essa configuração dupla de claves iguais é praticamente inexistente nos outros autores.

\section{5 - Práticas}

Finalmente, a última categoria de análise lida com os seguintes tipos de práticas adotadas nos métodos de LPV: práticas auditivas; práticas de acompanhamento e de tocar em conjunto; práticas de harmonia; práticas de transposição; práticas criativas (processos de criação e improvisação favoráveis ao desenvolvimento da LPV).

Práticas auditivas são inexistentes em todos os métodos analisados. Nenhum autor mostra real interesse neste quesito. 0 único recurso disponível foi o do CD disponível em RILEY e TERRY (2012) que não garante necessariamente algum tipo de treinamento dessa natureza. Por exemplo, o professor poderia fazer perguntas sobre o que se ouve, ressaltando algum aspecto melódico rítmico, harmônico ou da articulação da peça gravada.

Nos métodos analisados, são poucas as práticas de acompanhamento e de tocar em conjunto. Chamamos atenção para MANTAUX (2006), que apresenta padrões de acompanhamento da mão esquerda e da mão direita como melodia, em forma de arpejos. Apesar de KEMBER (2010) publicar um volume adicional para duetos, HARRIS (2012A e 2012B) é quem se sobressai com dois álbuns de duetos a serem tocados com o professor. Ele é o único que oferece material exclusivo para quatro mãos: um primeiro volume dedicado a uma fase de iniciação à LPV, anterior ao nível 1, com uso de escrita tradicional de pauta de cinco linhas e duas claves iguais, organizando os conteúdos de cinco a oito estágios. 0 segundo volume expõe outras tonalidades e figuras rítmicas, mantendo os padrões da ABRSM. Os acompanhamentos do professor são musicalmente interessantes e têm um grau de dificuldade ligeiramente acima do nível do aluno, permitindo que outros estudantes mais avançados possam tocar com seus pares.

Alguns dos métodos não oferecem práticas de harmonia (KEILMANN, 1972; JOHNSON, 2001; KEMBER, 2004; BULLARD, 2010; RILEY e TERRY, 2012). MEYER-GARFORTH (1984) apresenta o estudo de acordes, iniciando com a formação dos arpejos e depois dos acordes. Apesar de não oferecer uma prática de harmonia funcional básica, o método de HARRIS (2008) ilustra o funcionamento e a formação de acordes. Igualmente, MANTAUX (2006) oferece uma abordagem de formação de tríades, usando um recurso interessante que é executar lentamente 
vários acordes seguidos com mudanças internas das notas, mantendo sempre uma ou mais notas em comum. Já em BUCHER (2009), existe estudo e formação das tríades e suas inversões, classificação em maior, menor e diminuto e acorde de quatro sons com sétima maior e menor. A autora introduz a progressão de acordes com referência às cadências tonais mais comuns (IV-I; I-IV-I; I-II-V7-I; I-VI-II-V7). É, dentre os métodos analisados, o único que possui alguma referência de harmonia funcional. Porém, esse tópico ficou circunscrito apenas a poucas páginas de prática e não é retomado nas páginas seguintes, permanecendo um conhecimento condensado e isolado do restante da leitura.

Por fim, poucos métodos propõem práticas de transposição, como BULLARD (volume 6 a 8) e KEMBER (volume 3). BULLARD requisita a transposição para uma $2^{\mathrm{a}}$ maior, $4^{\mathrm{a}}$ e $5^{\mathrm{a}}$ justas acima e abaixo do original. KEMBER requisita do aluno a transposição das peças do primeiro volume com mãos separadas. Posteriormente, deve-se transpor as peças para uma tonalidade próxima, acima ou abaixo da tonalidade original. KEILMANN (1972, p.24-26) recomenda, além da transposição melódica, a de intervalos harmônicos e de tríades, a partir de intervalos de $2^{\text {as }} \mathrm{e}$ $3^{\text {as, }}$ maiores e menores, acima e abaixo da tonalidade original.

Sobre o uso de práticas criativas favoráveis ao desenvolvimento da LPV nos métodos, nenhum autor usou a improvisação como recurso em nenhuma atividade. Há aqueles que não sugerem ao aluno nenhum processo composicional ou de criação musical (KEILMANN, 1972; MEYERGARFORTH, 1984; JOHNSON, 2001; KEMBER, 2004; MANTAUX, 2006; BUCHER, 2009; RILEY e TERRY, 2012). Por outro lado, BULLARD (2010) é o único que instrui sobre aspectos criativos e imaginativos de composição, relacionando-os com a percepção auditiva e com a tonalidade aprendida naquela etapa, explorando-os de forma estruturada e bem integrada. Em alguns volumes, o autor apresenta uma composição semiestruturada, com baixo definido, devendo o aluno completar a melodia ou vice-versa, ou elaborar um baixo imitando um padrão rítmico dado anteriormente. Em outras atividades, o autor diversifica a proposta de criação, sugerindo o início melódico e rítmico das peças e instigando a sua continuidade pelo aluno, limitada apenas pelo número predefinido de compassos.

\section{3 - Discussão e conclusão}

As seções acima apresentaram um panorama dos principais conteúdos e características pedagógicas dos métodos de LPV para piano, analisados neste estudo. Esses conteúdos indicam as preocupações que seus autores têm no ensino dessa competência - o que precisa ser praticado e como deve ser praticado. A Figura 7 a seguir apresenta um quadro-síntese dos métodos de LPV ao piano, discriminando as demandas de formação que eles promovem.

Apesar de nenhum método ser completo, percebem-se pontos positivos nos diversos autores no sentido de construir um processo gradual e mais variado de aprendizagem da LPV: as atividades colaborativas (quatro mãos), a transposição, o treinamento em estilos, o uso de repertório além do sistema diatônico, mais diversificado em peças com caráter jazzístico, popular, boggie, pentatônica e outros. 


\begin{tabular}{|c|c|c|c|c|c|c|c|c|c|c|}
\hline \multirow[b]{2}{*}{ Categorias Gerais } & \multirow[b]{2}{*}{ Aspectos Específicos } & \multicolumn{9}{|c|}{ Autores de Métodos de LPV ao piano } \\
\hline & & $\begin{array}{l}\text { Bucher } \\
(2009)\end{array}$ & $\begin{array}{l}\text { Bullard } \\
(2010)\end{array}$ & $\begin{array}{l}\text { Harris } \\
(2008)\end{array}$ & $\begin{array}{l}\text { Johnson } \\
\text { (2001) }\end{array}$ & $\begin{array}{l}\text { Keilmann } \\
\text { (1972) }\end{array}$ & $\begin{array}{l}\text { Kember } \\
(2004)\end{array}$ & $\begin{array}{l}\text { Mantaux } \\
(2006)\end{array}$ & $\begin{array}{l}\text { Meyer- } \\
\text { Garforth } \\
(1984) \\
\end{array}$ & $\begin{array}{l}\text { Riley e } \\
\text { Terry } \\
(2012) \\
\end{array}$ \\
\hline \multirow{2}{*}{ Princípios Gerais } & Progressividade & $\mathrm{x}$ & $\mathrm{x}$ & $\mathrm{x}$ & $\mathrm{x}$ & $\mathrm{x}$ & $\mathrm{x}$ & $\mathrm{x}$ & $\mathrm{x}$ & $\mathrm{x}$ \\
\hline & Recursividade & $\mathrm{x}$ & $\mathrm{x}$ & $\mathrm{x}$ & $\mathrm{x}$ & & $\mathrm{x}$ & $\mathrm{x}$ & $\mathrm{x}$ & $\mathrm{x}$ \\
\hline \multirow{6}{*}{$\begin{array}{l}\text { Leitura de Notas e } \\
\text { Ritmo }\end{array}$} & $\begin{array}{l}\text { Segue as classificações da } \\
\text { ABRSM (Abordagem da Leitura } \\
\text { Dó Central Modificada) }\end{array}$ & & $\mathrm{x}$ & $\mathrm{x}$ & $\mathrm{x}$ & & & & $\begin{array}{l}\text { Nível III } \\
\text { (francês) }\end{array}$ & \\
\hline & $\begin{array}{l}\text { Amplitude intervalar inicial } \\
\text { (dentro da 5a.) }\end{array}$ & $\mathrm{x}$ & $\mathrm{x}$ & $\mathrm{x}$ & $\mathrm{x}$ & $\mathrm{x}$ & $\mathrm{x}$ & $\mathrm{x}$ & $\mathrm{x}$ & $\mathrm{x}$ \\
\hline & Percepção Visual da Partitura & $\mathrm{x}$ & & $\mathrm{x}$ & $\begin{array}{l}\text { (indicações } \\
\text { escritas antes } \\
\text { da LPV }\end{array}$ & $\begin{array}{c}\text { (colchetes } \\
\text { para os } \\
\text { motivos e } \\
\text { uso do tato) } \\
\end{array}$ & $\begin{array}{c}(\text { com } \\
\text { marcações na } \\
\text { partitura) }\end{array}$ & $\begin{array}{c}\text { Fermata (olhar } \\
\text { adiante) e } \\
\text { notas coloridas }\end{array}$ & \begin{tabular}{|c|} 
(indicações \\
escritas \\
antes da \\
LPV \\
\end{tabular} & $\mathrm{x}$ \\
\hline & Tempo (duração e compassos) & \begin{tabular}{|c|} 
simples: \\
binário, \\
ternário, \\
quaternário e \\
composto: \\
binário (seis \\
tempos) \\
\end{tabular} & & & & $\begin{array}{l}\text { bater e } \\
\text { cantar o } \\
\text { ritmo }\end{array}$ & & & & \\
\hline & Treinamento Rítmico & $\mathrm{x}$ & $\mathrm{x}$ & $\mathrm{x}$ & $\mathrm{x}$ & $\mathrm{x}$ & $\begin{array}{l}\text { (sobre as } \\
\text { peças do } \\
\text { repertório) }\end{array}$ & & $\mathrm{x}$ & $\mathrm{x}$ \\
\hline & Polifonia & & & (v. 8) & & & & $\mathrm{x}$ & & \\
\hline Aspectos Técnicos & Dedilhado & & $\begin{array}{c}\text { sem } \\
\text { graduação }\end{array}$ & & & & $\begin{array}{c}\text { não aparece } \\
\text { (v.3) }\end{array}$ & & & \\
\hline
\end{tabular}

Figura 7: Quadro-síntese de métodos de LPV e suas atividades pedagógicas. 


\begin{tabular}{|c|c|c|c|c|c|c|c|c|c|c|}
\hline \multirow[b]{2}{*}{ Categorias Gerais } & \multirow[b]{2}{*}{ Aspectos Específicos } & \multicolumn{9}{|c|}{ Autores de Métodos de LPV ao piano } \\
\hline & & $\begin{array}{l}\text { Bucher } \\
(2009)\end{array}$ & $\begin{array}{l}\text { Bullard } \\
(2010)\end{array}$ & $\begin{array}{l}\text { Harris } \\
(2008)\end{array}$ & $\begin{array}{c}\text { Johnson } \\
\text { (2001) }\end{array}$ & $\begin{array}{l}\text { Keilmann } \\
(1972)\end{array}$ & $\begin{array}{l}\text { Kember } \\
(2004)\end{array}$ & $\begin{array}{l}\text { Mantaux } \\
(2006)\end{array}$ & $\begin{array}{c}\text { Meyer- } \\
\text { Garforth } \\
\text { (1984) }\end{array}$ & $\begin{array}{l}\text { Riley e } \\
\text { Terry } \\
(2012)\end{array}$ \\
\hline \multirow{4}{*}{ Repertório } & Treinamento de Estilo & & & & & $\begin{array}{l}\text { (padrões do } \\
\text { período } \\
\text { clássico e } \\
\text { romântico) }\end{array}$ & (v. 3) & \begin{tabular}{|c} 
(Cap. 18) \\
Padrões de \\
acompanhame \\
nto na m.e. e \\
de melodia em \\
arpejos na m.d.
\end{tabular} & & \\
\hline & Formas Escalares & & $\begin{array}{l}\text { Pentatônica } \\
\text { e escalas de } \\
\text { jazz }\end{array}$ & \begin{tabular}{|l|} 
Pentatônica \\
e escalas de \\
jazz
\end{tabular} & & & & & & \\
\hline & Variedade do Repertório & & $\begin{array}{c}\text { (Ragtime, } \\
\text { Romance, } \\
\text { Boogie, } \\
\text { Valsa, } \\
\text { Bourée, } \\
\text { Mazurca v. } \\
6 \text { a 8) } \\
\end{array}$ & $\begin{array}{c}\text { (Baixo } \\
\text { d'Alberti e } \\
\text { variantes, } \\
\text { walking } \\
\text { bass, } \\
\text { ragtime) }\end{array}$ & & $\begin{array}{c}\text { Tema com } \\
\text { variações, } \\
\text { Forma- } \\
\text { sonata }\end{array}$ & & & $\begin{array}{l}\text { gavota, } \\
\text { minueto e } \\
\text { valsa }\end{array}$ & \begin{tabular}{|l} 
Tema com \\
variações, \\
ABA, rondó
\end{tabular} \\
\hline & $\begin{array}{l}\text { Atividades de Reforço } \\
\text { (coletânea) }\end{array}$ & $\mathrm{x}$ & $\mathrm{x}$ & & $\mathrm{x}$ & $\mathrm{x}$ & v. extra & & $\mathrm{x}$ & $\begin{array}{c}\text { (Cd } \\
\text { gravado das } \\
\text { peças) }\end{array}$ \\
\hline \multirow{6}{*}{ Práticas } & Práticas Auditivas & & & & & & & & & $\begin{array}{c}\text { (Cd } \\
\text { gravado das } \\
\text { peças) }\end{array}$ \\
\hline & Acompanhar uma melodia & & & & & & $\mathrm{x}$ & & & \\
\hline & 4 mãos & & $\mathrm{x}$ & $\begin{array}{l}\text { (Duetos, } \\
2012)\end{array}$ & & & (v. 3) & & & \\
\hline & Harmonia Funcional & $\mathrm{x}$ & & & & & & & & \\
\hline & Transposição & & (v. 6 a 8$)$ & & & $\mathrm{x}$ & (v. 3) & & & \\
\hline & \begin{tabular}{|l|} 
Criação Composição \\
Improvisação
\end{tabular} & & $\mathrm{x}$ & & & & & & & \\
\hline
\end{tabular}

Figura 7 (cont.): Quadro-síntese de métodos de LPV e suas atividades pedagógicas. 
Assim, considerando a síntese dos quadros da Figura 7, este artigo apresentou resumidamente vários aspectos para a pedagogia da LPV: a) algumas estratégias genéricas para o estudo da competência; b) algumas peculiaridades relacionadas à percepção visual e à qualidade do repertório; c) algumas estratégias de desenvolvimento como treinamento rítmico, atividades criativas e colaborativas, treinamento de estilos musicais, harmonia e transposição.

A análise dos métodos e as reflexões aqui apresentadas sugerem que a LPV é uma competência de múltiplas perspectivas. Como foi indicado anteriormente (SANTIAGO e SAMPAIO, 2014), essas multiplicidades se manifestam também a partir de fatores biológicos, genéticos, cognitivos e pedagógicos. Isoladamente, nenhum desses fatores seria suficiente para o pleno desenvolvimento da prática da LPV ao piano. Integradamente, por outro lado, os fatores apresentados poderão configurar um caminho mais eficiente para a prática da LPV.

Entendemos que a aquisição de competência em LPV requer uma pedagogia especializada que não se satisfaz em apenas estudar o instrumento ou em executar obras pianísticas. Os métodos de LPV são importantes por desenvolverem estratégias diversificando-as em um corpo de princípios e ações didáticas baseadas na experiência e exercício de seus autores.

Apesar de os autores dos métodos usarem muitos recursos, estamos longe ainda de uma pedagogia abrangente da LPV, decodificada em um 'método' com padrão-ouro de qualidade e que contemple todas as ações necessárias da aprendizagem, oferecendo a professores de piano a possibilidade de testá-las. Ainda assim, muitos dos aspectos discutidos neste estudo carecem de mais investigação e aprofundamento, dentre os quais: a) melhoria das estratégias em leitura da escrita polifônica; b) o uso de transposição como ferramenta efetiva no aprendizado dessa competência; c) o uso da LPV em claves diferentes das de Sol e Fá; d) a leitura para escrita coral a 4 vozes; e) a LPV específica para a música atonal no piano.

Existe um amplo corpo de pesquisa em LPV que poderá iluminar os caminhos da pedagogia. Pretendemos dar continuidade ao estudo da LPV ao piano e trazer à tona muitas das pesquisas que têm contribuído para o avanço das nossas investigações, observando as especificidades da LPV que elas discutem, bem como seus procedimentos metodológicos, relação com a pedagogia e resultados. Este é assunto para os próximos artigos. Mas fato é que nossa motivação pelo tema impulsiona investigações futuras, tendo em vista o eterno desafio de obter melhores resultados na prática da LPV. Ao fim de toda essa discussão, a maior motivação continua sendo aquilo que nos trouxe a esta temática de pesquisa: a busca por uma pedagogia competente em LPV ao piano.

\section{Referências}

1. BUCHER, Hannelore (2009). Leitura à Primeira Vista: a Ciência da Conquista. Vitória: Edição da autora.

2. BULLARD, Alan (2010). Joining the Dots 1 to 8: a Fresh Approach to Piano Sight-Reading. London: ABRSM, $8 \mathrm{v}$.

3. GABRIELSSON, Alf (1999). The Performance of Music. In: The Psychology of Music. 2. ed. Org. by Deutsch, Diana. Oxford: Oxford Academic Press, p.501-602. 
SAMPAIO, Marcelo A.; SANTIAGO, Patrícia F. (2018). Contribuições dos métodos de ensino para o desenvolvimento da leitura à primeira vista ao piano. Per Musi. Belo Horizonte: UFMG. p.1-17.

4. HARRIS, Paul (2008). Improve Your Sight-Reading!: Grade 4 to 8: Piano. London: Faber Music, 9v.

5. ___ (2012A). Improve your Sight-Reading!: Duets: Grades 0-1. London: Faber Music, 2v.

6. ___ (2012B). Improve your Sight-Reading!: Duets: Grades 2-3. London: Faber Music, 2v.

7. ___ (2013A). Improve Your Sight-Reading!: Initial Piano. London: Faber Music. 9v.

8. ___ (2013B) Improve Your Sight-Reading!: Grade 1 to 3: Piano. London: Faber Music, 9v.

9. JOHnSON, T. A (2001). Right a Sight: Piano Grade One to Eight. London: Peter's, 8v.

10. KEILMANN, Wilhelm (1972). Introduction to Sight Reading: at the Piano or Other Keyboard Instrument. Trad. Kurt Michaelis. Frankfurt: Henry Litolff - Peter's.

11._ (1975). Ich Spiele vom Blatt II: Schule des Prima-Vista-Spiels fur Klavier und Andere Tasteninstrumente. Frankfurt: Henry Litolff - Peter's, 1975.

12.KEMBER, John (2004). Piano sight-reading 1: a fresh approach. London: Schott, 4v.

13. _ (2005). Piano sight-reading 2: a fresh approach. London: Schott, 4v.

14.___ (2008). Piano sight-reading 3: a fresh approach. London: Schott, $4 \mathrm{v}$.

15.___ (2010) More Piano Sight-Reading: Additional Material for Piano Solo and Duet. London: Schott, 4v.

16.LEHMANN, A.; McARTHUR, Victoria (2002). Sight-Reading. In: The Science and Psychology of Music Performance: Creative Strategies for Teaching and Learning. Org. by Parncutt, Richard; McPherson, G. E. Oxford: Oxford University Press, p.135-150.

17.LEHMANN, A.; SLOBODA, J. A.; WOODY, Robert H. (2007). Psychology for Musicians: Understanding and Acquiring the Skills. Oxford: Oxford University Press.

18. MANTAUX, Anne (2006). Méthode de Déchiffrage pour Piano. Paris: Gérard Billaudot.

19. MEYER-GARFORTH, Catherine (1984). Cours Progressive de Déchiffrage pour le Piano. Charnay-lès-Mâcon (France): Robert Martin.

20. RAMOS, Ana Consuelo (2005). Leitura Prévia e Performance à Primeira Vista no Ensino do Piano Complementar: Implicações e Estratégias Pedagógicas a Partir do Modelo C(L)A(S)P de Swanwick. Belo Horizonte: Dissertação de Mestrado, Escola de Música, Universidade Federal de Minas Gerais.

21. RILEY, Malcolm; TERRY, Paul (2012). Sight Reading Success: Piano Grade 1 to 5. London: Rhine Gold education, $5 \mathrm{v}$.

22. RISARTO, M. E. F (2010). A Leitura à Primeira Vista e o Ensino de Piano. Dissertação de Mestrado. Escola de Música. São Paulo: Universidade Estadual Paulista.

23. ROSEMANN, S.; ALTENMULLER, E.; FAHLE, M. (2015). The art of sight-reading: influence of practice, playing tempo, complexity and cognitive skills on the eye-hand span in pianists. Psychology of Music. v.44, n.4, p.658673.

24.SAMPAIO, M. A. (2001). Métodos Brasileiros de Iniciação ao Piano: um Estudo sob o Ponto de Vista Pedagógico. Dissertação de Mestrado em Música, Centro de Letras e Artes. Rio de Janeiro: Universidade Federal do Estado do Rio de Janeiro. 
25. _ (2017). As Estratégias Pedagógicas para a Leitura à Primeira Vista ao Piano. Tese de Doutorado em Música, Escola de Música. Belo Horizonte: Universidade Federal de Minas Gerais.

26.SAMPAIO, Marcelo Almeida; SANTIAGO, Patrícia Furst (2013). Leitura à primeira vista: um estudo do desenvolvimento das capacidades cognitivas e das habilidades musicais do pianista. In: Anais do XXI Congresso da Associação Brasileira de Educação Musical. Pirenópolis: Universidade de Brasília, p.12521266.

27.SANTIAGO, Patrícia Furst; SAMPAIO, Marcelo Almeida (2014). Factors that influence piano sight reading and their implications for the education of professional musicians. In: Proceedings of the International Society for Music Education. Org. by Forrest, David. Porto Alegre, Brazil: p.271-278.

Nota sobre os autores:

Marcelo Almeida Sampaio ensina piano e leitura à primeira vista na Universidade do Estado de Minas Gerais, em Belo Horizonte. Tem graduação em piano pela Universidade Estadual de Campinas (Unicamp, 1996), Especialização em piano e música de câmara pela State Academy of Music (Sófia, Bulgária, 1998), Mestrado em Música pela Universidade Federal do Estado do Rio de Janeiro (Unirio, 2001) e Doutorado em Música (UFMG, 2017), na linha da Educação Musical, com doutorado-sanduíche no Institute of Education pela University College London na Inglaterra, com temática em leitura à primeira vista dos pianistas. Atua profissionalmente como pianista colaborador e camerista.

Patrícia Furst Santiago tem graduação em Piano pela Escola de Música da UFMG (1982). Especialização em Educação Musical pela Escola de Música da UFMG (1985). Mestrado (2001) e Doutorado em Educação Musical (2004) pelo Institute of Education, University of London. Realizou formação para professores da Técnica Alexander no Constructive Teaching Centre, Londres (2001/2003). É professora na Escola de Música da UFMG desde 2009, atuando na Educação Musical. Desenvolve pesquisa nas áreas de Educação Musical, Pedagogia do Piano e Técnica Alexander. 